\title{
A Perdigão e a formação de um business group no Brasil: características e estratégias (1934-2009)
}

\section{Perdigão and the formation of a business group in Brazil: characteristics and strategies (1934-2009)}

\author{
Angelo B. Zanela ${ }^{1, *}$ * (D) 0000-0002-5746-1305 \\ Armando J. Dalla Costa ${ }^{2}$ iD 0000-0002-1016-7491
}

${ }^{1}$ Universidade Federal da Fronteira Sul, Chapecó, Brasil.

${ }^{2}$ Universidade Federal do Paraná, Paraná, Brasil.

*Correspondencia: abzanela@yahoo.com.br

Resumo. O principal objetivo deste trabalho foi apresentar a Perdigão, S. A., como um modelo de business group consolidado no Brasil entre 1934-2009. Submersa em um cenário repleto de instabilidades e incertezas que costumam caracterizar as economias periféricas, a Perdigão promoveu estratégias que permitiram diferenciá-la da maioria das grandes empresas consolidadas em economias maduras. Portanto, concluímos que ao longo de seus 75 anos de história, a Perdigão caracterizou-se como um modelo organizacional business group capaz de adotar estratégias que permitiram explorar as sinergias criadas pelas atividades complementares entre os setores de carnes e derivados e se consolidar entre as maiores da indústria de alimentos no Brasil.

Palavras-chave: Perdigão; business group; Brasil

Abstract. The main objective of this work was to present Perdigão, S. A., as a model of a business group consolidated in Brazil between 1934-2009. Submerged in a scenario full of instabilities and uncertainties that usually characterize peripheral economies, Perdigão promoted strategies that allowed it to differentiate

CÓMO CITAR: Zanela, A. B. y Dalla Costa, A. J. (2022). A Perdigão e a formação de um Business Group no Brasil: características e estratégias (1934-2009). América Latina en la Historia Económica, 29(1), 1-28. DOI: 10.18232/20073496.1180 
it from most large companies consolidated in mature economies. Therefore, we conclude that throughout its 75 years of history, Perdigão has been characterized as a business group organizational model capable of adopting strategies that allowed it to exploit the synergies created by the complementary activities between the meat and meat products sectors and consolidate itself among the largest of the food industry in Brazil.

Key words: Perdigão; business group; Brazil

JEL: N5; N8; N66

Recebido: 26 de fevereiro de 2020.

Aceito: 07 de maio de 2021.

Publicado: 03 de setembro de 2021.

\section{INTRODUÇÃO}

As opiniões de Gerlach (1992), Granovetter (2005), Yiu, Lu, Bruton e Hoskisson (2007), Carney, Gedajlovic, Heugens, Van Essen, e Van Oosterhout (2011), Fernández-Pérez e Lluch (2016) e de outros autores importantes, permitem estabelecer diferenças entre as características que descrevem os grupos econômicos estabelecidos em economias menos desenvolvidas e as características que definem as estruturas identificadas como conglomerados, holdings (H) e multidivisionais (M) descritas por Williamson (1975). Por exemplo, embora a coordenação nos conglomerados ocorra por meio do controle interno unificado de um portfólio de empresas, a coordenação nos businesses groups (em diante BG's) se baseia em uma rede mais complexa de mecanismos, como patrimônio múltiplo e recíproco, composição das dívidas e forma de comércio, vínculos socioculturais e afiliação de parentesco entre os principais gerentes.

A Perdigão foi fundada pelas famílias Ponzoni e Brandalise em 1934, na região Oeste de Santa Catarina (Brasil). Em 2009, era reconhecida como uma das maiores empresas brasileiras do ramo de alimentos (Brasil Food [BRF], 2009). O desenvolvimento e a história dessa estrutura organizacional revelam as características de uma empresa que iniciou suas atividades sob a forma de gestão familiar que se destacou pelo enfrentamento das dificuldades impostas pelo seu ambiente de inserção durante etapas importantes de seu processo de expansão. Mas, apesar da importância atribuída à gestão familiar para a consolidação da Perdigão como um modelo de diante BG's no Brasil, surgiram evidências de que, na metade dos anos 1990, as dificuldades financeiras aumentaram consideravelmente, dando a sensação de que a solução para os problemas vigentes passava pela transferência do controle acionário, além da adoção de uma gestão mais profissionalizada. E, sob a orientação de uma gestão profissional, o grupo Perdigão buscaria alcançar suas metas planejadas, conciliando as estratégias de crescimento com a sustentabilidade financeira.

Por outro lado, a mudança na forma de gestão não promoveu a descontinuidade de ações estratégicas que estimulavam esse grupo empresarial a preservar os vínculos socioculturais que permitiam a transferência de conhecimentos e a formação de laços sociais como parte das estratégias que poderiam levar ao sucesso dos seus empreendimentos a partir da geração de uma cultura corporativa comum. Estratégias que também estiveram baseadas na verticalização e na diversificação de produtos e atividades, no desenvolvimento de novas tecnologias e na formação de um sistema de integração com produtores locais. Isto significa dizer que, na prática, por meio de estratégicas 
sinergicamente estabelecidas, a Perdigão promoveu atividades que iam desde o processamento de rações para a criação de animais de corte à distribuição dos produtos derivados da carne de aves, suína e bovina.

Com as atenções voltadas para o novo milênio, a Perdigão buscou adequar seu sistema produtivo a uma economia mundialmente globalizada, buscando internacionalizar suas atividades ou criar novos produtos para atender as necessidades dos consumidores em potencial, dentro e fora do território nacional.

Em 19 de maio de 2009, depois de algumas tentativas malogradas para consolidar sua associação com a Sadia, S. A., a Perdigão, enfim anunciou a fusão com sua principal concorrente como parte de um conjunto de estratégias que antes mesmo de serem consolidadas, fizeram com que o mercado financeiro sinalizasse para a possibilidade de ganhos monetários expressivos e porcentagens ainda maiores de market share.

Dito isto, esperamos que este trabalho se torne produtivo à medida que apresente o grupo Perdigão como uma estrutura organizacional formada no Brasil, cujas características gerais e estratégias adotadas para o seu crescimento, ajudem a explicar as diferenças quanto à formação e consolidação dos grupos formados em regiões periféricas, em relação às estruturas organizacionais formadas e consolidadas em economias maduras.

Embora já existam trabalhos a respeito do grupo Perdigão, como os de Brandalise (1982); Tassara e Scapin (1996); Dalla Costa (2005, 2007) e Sereia, Gabardo e Vieira (2011), no entanto, nenhum deles trabalha com a história da Perdigão do ponto de vista da concepção dos BG's. Este texto vem, portanto, contribuir com a historiografia empresarial do país ao analisar a história do grupo Perdigão sob um novo olhar, tendo esta teoria como pano de fundo na análise.

Para tanto, além desta introdução, o presente trabalho conta com mais quatro seções. A seção dois apresenta uma revisão teórica, trazendo algumas das principais características associadas às estruturas organizacionais do tipo BG's, reconhecidas na América-Latina como grupos econômicos. A seção três discute as estratégias e as características que podem definir a Perdigão como um modelo de BG's consolidado no Brasil. Dividida em etapas, esta seção permitirá que se observe como as formas de gestão familiar e profissional desenvolveram seus planos de expansão e participação no mercado interno e externo, até transformar a Perdigão em um dos mais importantes grupos nacionais, operando no setor de carnes e derivados. Enquanto a seção quatro trata das considerações finais, a cinco apresenta as referências.

\section{BUSINESS GROUPS: UMA BREVE REVISÃO TEÓRICA}

Segundo Yiu et al. (2007) até meados dos anos 2000 as pesquisas sobre BG's continuavam altamente fragmentadas. Desta forma o surgimento de uma estrutura sistemática e integrativa para entender esses grupos de negócios tornava-se necessária.

Ainda hoje, o estudo sobre as estruturas de BG's continua exigindo dos pesquisadores uma definição mais refinada, estabelecendo assim um conceito geral que abarque tanto a origem, quanto as estratégias e o desempenho necessários à consolidação destes grupos nas chamadas regiões anfitriãs.

Khanna e Rivkin (2001, p. 47), por exemplo, procuraram cobrir essa lacuna definindo que as estruturas BG's são empresas que "embora legalmente independentes, estão ligadas por uma constelação de laços formais e informais, estando acostumadas às ações coordenadas”. Por sua vez, Granovetter (2005) argumentou que a maioria das teorias existentes sobre BG's concentra-se na 
ideia de que os grupos empresariais emergem de uma única empresa adquirida, ou a partir da geração de múltiplas firmas relacionadas ou subordinadas, ou de um conjunto de empresas anteriormente independentes sem uma companhia central clara que organize as demais empresas do grupo. Cuervo-Cazurra (2006) chamou a atenção para o fato de que as maiores empresas em muitos países em desenvolvimento são amplamente diversificadas e possuem vários elos com muitas outras firmas. Nesse sentido, Barbero e Puig (2016) ressaltam que "a maioria dos historiadores parece confortável com as definições propostas por Granovetter (2005) e Khanna e Yafeh (2010), entendendo que tais grupos emergem das atividades de diversificação promovidas por uma única empresa".

Para Carney et al. (2011) as várias discussões reunidas pela literatura especializada promoveram alguns pontos consensuais. Um deles diz respeito aos BG's estarem onipresentes em muitos países e, até por isso, a eles foram atribuídos diferentes conceitos. No Japão, por exemplo, os três Zaibatsus (Mitsui, Mitsubishi e Sumitomo) referiam-se a grupos piramidais controlados por famílias, com empresas privadas no topo e subsidiárias amplamente diversificadas, desde finanças e comércio até manufatura e mineração (Miyajima e Kawamoto, 2010). Na Coréia do Sul, Chang (2003) apresenta os grupos empresariais coreanos Chaebols, os quais controlam as empresas afiliadas através de participações acionárias diretas e piramidais, embora essas afiliadas constituam firmas legalmente independentes com seus próprios acionistas e conselhos de administração. Na América Latina, os chamados grupos econômicos são considerados como estruturas fundamentais para os países em desenvolvimento, geralmente, identificadas como grandes conglomerados diversificados que dominam a atividade econômica (Ghatak e Kali, 2000).

Na Rússia, a estrutura oligopolista da indústria, a natureza segmentada dos fluxos de informação e os mercados de capital subdesenvolvidos, deram margem ao desenvolvimento de grupos empresariais definidos como Russia's Oligarchs (Perotti e Gelfer, 2001).

$\mathrm{Na}$ Ásia, entre as características mais importantes dos grandes grupos empresariais chineses estão as entidades multi-industriais de propriedade do Estado e os pequenos grupos empresariais de propriedade familiar (Lee e Sam-Kang, 2010). No caso da Índia, as India’s Business Houses atuam junto ao governo para obter uma parcela desproporcionalmente grande de licenças industriais (Sarkar, 2010).

Outro ponto consensual surge quando se considera os BG's como estruturas empresariais que são estruturalmente diferentes dos tipos conglomerados. Gerlach (1992), Granovetter (2005), Yiu et al. (2007), Carney et al. (2011) chamam a atenção para o fato de que embora a coordenação nos conglomerados ocorra por meio do controle interno unificado de um portfólio de empresas, a coordenação nos BG's se baseia em uma rede mais complexa de mecanismos, como patrimônio múltiplo e recíproco, composição das dívidas e forma de comércio, vínculos socioculturais e afiliação de parentesco entre os principais gerentes.

Nesse sentido vale ressaltar diferenças importantes entre as estruturas BG's e as descritas pelo ideário de Chandler-Williamson baseadas nas organizações nas formas (H) holdings e (M) multidivisionais que, inclusive, possuem diferenças entre si. As empresas multidivisionais (M) são representadas por grandes empresas em economias maduras -diferentemente dos grupos de negócios diversificados que proliferaram em economias emergentes.

Apesar disso, estruturas do tipo holding, multidivisional e BG's são definidas como tendo características idênticas. $\mathrm{O}$ fato é que enquanto as estruturas organizacionais multidivisionais $(\mathrm{M})$ são formadas com base nos modelos de gestão e nos ambientes institucionais anglo-americanos, as estruturas BG's comumente estabelecidas em economias emergentes costumam formam-se e se 
adaptarem às realidades distintas associadas a cada região. Para Colpan, Hikino e Slaibe (2010) a identificação de BG's como estruturas do tipo $(\mathrm{H})^{1}$ pode ser enganosa, a menos que essa classificação seja claramente definida no contexto explícito de estruturas organizacionais específicas.

É comum admitir que os BG’s têm capacidade de adaptação às condições regionais marcadas pelas incertezas conjunturais e pela necessidade de construção de um ambiente onde os sistemas econômicos ainda precisam adquirir mercados que funcionem bem e instituições que apoiem as economias capitalistas. Contudo, é razoável presumir que as adversidades enfrentadas durante o processo de formação dos grupos em âmbito regional são apenas parte de um complexo conjunto de elementos que embasam as discussões sobre o papel desempenhado pelas respectivas estruturas organizacionais durante o processo de desenvolvimento de algumas economias. Na maioria das vezes, tais discussões criam incentivos para classificar estas estruturas organizacionais como fenômenos sociais e econômicos complexos e que servem a diversos propósitos. No entanto, não levam em consideração a criação de efeitos múltiplos, conflitantes e complementares nas regiões de inserção, assim como nas empresas afiliadas (Gerlach, 1992; Keister, 1998).

Paloma Fernández-Pérez e Andrea Lluch (2016) ressaltam que não existe um modelo de negócios latino-americano, nem um padrão institucional comum que represente um modelo capitalista estabelecido neste território. Nesse caso, dependendo da região onde estão inseridos, os gestores empresariais deparam-se com contingências institucionais e com a heterogeneidade relacionada à formação das estruturas organizacionais de suas afiliadas. Sendo assim, serão adotadas, constantemente, ações inovadoras frente aos efeitos adversos provocados por falhas de mercado, custos burocráticos, legislação precária e ineficiente e falta de infraestrutura adequada. ${ }^{2}$

Yiu et al. (2007) classificam as organizações BG's como tipos de estruturas empresariais controladas por entidades centrais, compostas por um proprietário fundador ou um grupo familiar. Martins (1965), Montmorillon (1986), Bernhoeft (1989), Gaj (1989) e Fernández-Pérez e Lluch (2016) consideram que estas entidades centrais podem ser as famílias, as cooperativas, entidades estatais ou estrangeiras. Para Gonçalves (1991) o controle destes grupos pode ser exercido de forma societária, por meio da reunião de um número grande ou significativo de empresários isolados. Nesse caso, os proprietários do capital podem distribuir entre si (ou entre os membros das suas famílias) os postos de direção do grupo, mas tendem, geralmente, a contratar administradores profissionais.

É importante ressaltar que empresa familiar é uma entidade central de controle que assume vários significados, ainda que se considere as importantes interpretações de Carney et al. (2011), rejeitando análises monoteóricas baseadas nas formas de propriedade e controle estabelecidas no ambiente de negócios. Muritiba, Muritiba, Domingues, Di-Dio e Zavarizzi (2016) entendem que dependendo das variáveis que se deseja trabalhar e dos objetivos estabelecidos em cada estudo, serão aceitas as definições elaboradas por um ou mais autores. Donneley (1976), Nogueira (1984), Bernhoeft (1989), Gaj (1989), Gonçalves (1991), Lodi (1989), Rosenblatt (1995), Gorgati (2000)

${ }^{1}$ Williamson (1975, p. 144) concluiu que: "as empresas holding certamente não podem ser esperadas de forma confiável para produzir resultados que se comparam favoravelmente às estruturas organizacionais da forma M [multidivisional]". Segundo Colpan, Hikino e Slaibe (2010) Williamson entendeu que a holding é uma estrutura executiva fraca que representava a divisão de um tipo muito limitado, correspondendo ao seu portfólio de produtos, estreito e relacionado. Williamson (1975, p. 144) acabaria concluíndo que: "as empresas holding certamente não podem ser esperadas de forma confiável para produzir resultados que se comparam favoravelmente às estruturas da forma $\mathrm{M}$ [multidivisional]".

${ }^{2}$ Véanse Gerlach (1992); Keister (1998); Gedajlovic e Shapiro (2002); Cuervo-Cazurra (2007); Yiu et al. (2007); Carney et al. (2011) e Fernández-Pérez e Lluch (2016). 
e Fernández-Pérez e Lluch (2016), por exemplo, acreditam que as empresas familiares podem ser definidas com "desenvolvimento tridimensional" desenvolvido por Gersick, Hampton e Lansberg (1998), ${ }^{3}$ e que se refere ao desenvolvimento das empresas familiares e a passagem de poder entre as gerações, onde se observa que o eixo de desenvolvimento da propriedade passa por três estágios principais. No primeiro estágio, de desenvolvimento da empresa, o proprietário controlador é responsabilizado pela fundação da firma e pelo controle de todas as ações administrativas. Em seguida, surge a sociedade entre irmãos, quando gradativamente os filhos ou os genros assumem cargos importantes na gestão empresarial. Adiante, ocorre a passagem para o consórcio de primos, no qual a direção passa a ser exercida pela terceira geração da família.

Observa-se assim que parte dos autores supracitados entendem que a propriedade e o controle empresarial são executados pela família em pelo menos duas gerações, sendo que a forma de controle familiar ocorre no momento de sua fundação. Alguns deles, porém, ressaltam a importância dos vínculos socioculturais, dos valores institucionais e do espírito empreendedor do fundador para a formação e crescimento da empresa.

Assim sendo, parece estar claro que o conceito de grupo familiar leva em consideração que a propriedade e o controle dos negócios são estabelecidos, inicialmente, no momento da fundação e de definição do core business empresarial e com base no caráter empreendedor do fundador. Sob a gestão familiar a organização parece ser capaz de se desenvolver e formar uma coleção de empresas legalmente independentes, estabelecidas por vínculos econômicos (como propriedade, financeiros e comerciais) e sociais (como família, parentesco e amizade). Nesse contexto, ainda se presume uma maior aproximação entre a empresa e seus colaboradores, já que a administração familiar acredita ser preciso promover ações em prol do crescimento profissional e valorização desses colaboradores e seus dependentes.

No que se refere a gestão profissionalizada Leach (1984) diz que esta forma de gestão está estreitamente associada à mudança de estilo gerencial do proprietário em razão das necessidades de crescimento, como consequência do mercado que a empresa faz parte. Assim, a mudança na forma de gestão ocorre a partir de um método de gerenciamento instintivo, para uma abordagem profissionalizada, que por sua vez, está baseada no planejamento e controle do crescimento por meio de técnicas estratégicas de administração. Segundo Flores, Campos e Sonza (2019) os processos de profissionalização e abertura de capitais em âmbito organizacional, passaram a ser exigidos diante dos novos formatos de estruturas organizacionais que se organizaram conforme as relações dos atores representados por executivos e acionistas de empresas com propriedade dispersa do capital. Ou seja, emergiram estruturas de propriedade piramidal, definidas como uma cadeia hierárquica de relações de propriedade, onde indivíduos ou famílias controlam várias empresas. Para Valadare e Leal (2000) essas estruturas buscam manter o controle da firma dentro da mesma família, evitando que outros detentores de grandes blocos de ações lançadas em mercado aberto contestem esse controle.

${ }^{3}$ Gersick et al. (1998) formularam o conceito de "desenvolvimento tridimensional" da empresa familiar, envolvendo a empresa, a família e a propriedade. Para Dalla Costa (2005) o conceito de “tridimensionalidade” proposto em Gersick et al. (1998) é capaz de fornecer as ferramentas necessárias à compreensão dos diversos mecanismos de funcionamento de uma família em sua empresa e, por isso, é tomado como referência para as discussões a respeito da passagem do poder em empresas familiares. 
Segundo Almeida e Wolfenzon (2006) e Aldrighi e Postali (2010) a propriedade piramidal passou a representar uma forma de organização bastante disseminada entre as empresas de capital aberto no Brasil, onde alguns acionistas controladores, provavelmente, passaram a utilizar as formas piramidais como um mercado interno de capitais para o financiamento de novos empreendimentos.

Outras abordagens a respeito dos grupos econômicos brasileiros mostram que as estruturas empresariais nacionais procuraram adotar estratégias verticalizantes e diversificadoras sinérgicas, tentando assim estabelecer uma relação entre a estrutura já existente e sua reformulação (Machado, 1996). Ainda segundo o autor, esses grupos concentraram seus esforços nas conquistas dos espaços internos e externos e no aproveitamento das oportunidades tecnológicas. Também destacaram a importância do planejamento e da expansão empresarial de longo prazo frente aos movimentos gerais provocados pela instabilidade macroeconômica.

Nesse contexto, Aldrighi e Postali (2010) ressaltam que os grupos econômicos brasileiros passaram a ser protagonistas no cenário corporativo nacional e seus investimentos foram requisitados pelas sucessivas administrações nacionais ao longo do tempo. Com base no método de abordagem utilizado pelos autores (2010), o quadro 1 procura apresentar alguns dos principais grupos

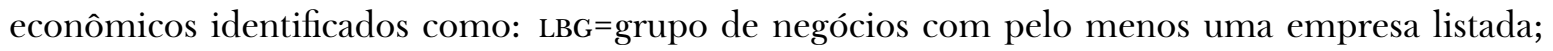
DBG= grupo de negócios diversificado ou grupo de negócios diversificado em pelo menos três setores; $\mathrm{LBG}+\mathrm{DBG}=\mathrm{um}$ grupo de negócios de empresas listadas e diversificadas (um grupo de negócios composto por, pelo menos, uma empresa afiliada listada e ao mesmo tempo diversificado em pelo menos três setores); $\mathrm{BRS}=$ grupo controlado pelo estado brasileiro; $\mathrm{BRP}=$ grupo brasileiro de controle privado; $\mathrm{BRP}-\mathrm{FR}=$ grupo brasileiro de controle privado-francês.

Guillén (2010) considera que as formações de alguns grupos econômicos latino-americanos só foram influenciadas pelo apoio governamental e pelas relações sociais em determinado momento de condições econômicas e sociais locais, e tais relações não estão, necessariamente, na origem de grupos que surgem como organizações privadas. No entanto, vale ressaltar que entre os anos 1940 e 1950, o governo de Getúlio Vargas assumiu o processo de diversificação industrial, já que o capital privado não desfrutava de condições financeiras para investir em empresas de capital intensivo (Machado, 1996). Isso pode explicar, em parte, como os principais grupos empresariais brasileiros cresceram e expandiram suas atividades até o final da década de 1960 a partir de indústrias leves, alimentos, comércio varejista, bancos, energia elétrica e construção civil, beneficiando-se das relações com o Estado brasileiro.

\section{A Perdigão como um modelo de Business Group no Brasil}

Características e estratégias do grupo Perdigão entre as décadas de 1930 e 1950

Entre as características que contribuem para classificar a Perdigão como um modelo organizacional BG's, estão os fatores de ordem social e cultural. As influências destes fatores sobre as formas de gerenciamento da Perdigão ao longo do tempo podem ser observadas já no momento da chegada dos irmãos Angelo e Pedro Ponzoni e Giovanni e Ricardo Brandalise ao Vale do Rio do Peixe em 1916. Descendentes de italianos e alemães, Angelo e Pedro Ponzoni e Giovanni e Ricardo Brandalise viveram as transformações ocorridas a partir de 1920 nas paisagens da região da Vila Perdizes (colonizada por italianos) e da Vila de Vitória (colonizada por alemães) em virtude do crescimento dos trigais, vinhedos e da chegada de mais imigrantes. 
QUADRO 1. PRINCIPAIS GRUPOS ECONÔMICOS BRASILEIROS (1808-1969)

\begin{tabular}{lccc}
\hline & & & Origem \\
Empresa & Ano & Tipo & do capital \\
\hline Banco do Brasil, S. A. & 1808 & LBG & BRS \\
Gerdau, S. A. & 1901 & LBG+DBG & LBG \\
Companhia Paulista de Força e Luz [CPFL] Energia, S. A. & 1912 & LBG & LBG \\
Votorantim, S. A. & 1891 & LBG+DBG & LBG \\
Unibanco, S. A. & 1924 & LBG & LBG \\
Lojas Americanas, S. A. & 1929 & LBG & LBG \\
Perdigão, S. A. & 1934 & LBG & LBG \\
Ultrapar Participações, S. A. & 1937 & LBG+DBG & LBG \\
Camargo Correa, S. A. & 1939 & LBG+DBG & LBG \\
Companhia Siderúrgica Nacional, S. A. & 1941 & LBG+DBG & LBG \\
Vale, S. A. & 1942 & LBG+DBG & LBG \\
Banco Bradesco, S. A. & 1943 & LBG+DBG & LBG \\
Odebrecht, S. A. & 1944 & LBG+DBG & LBG \\
Sadia, S. A. & 1944 & LBG & LBG \\
Grupo Pão de Açúcar & 1948 & LBG & LBG-fr \\
Andrade Gutierrez, S. A. & 1948 & LBG+DBG & LBG \\
Companhia Energética de Minas Gerais, S. A. & 1952 & LBG & LBG \\
Petróleo Brasileiro, S. A. & 1953 & LBG+DBG & BRS \\
Companhia Paranaense de Energia (Copel) & 1954 & LBG & BRS \\
Usinas Siderúrgicas de Minas Gerais, S. A. & 1956 & LBG+DBG & LBG \\
Transportes aéreos regionais [TAM] & 1961 & LBG+DBG & LBG \\
Eletrobras & 1962 & LBG & BRS \\
Embraer & 1969 & LBG & LBG \\
\hline
\end{tabular}

Fonte: elaboração própria com base em Aldrighi e Postali (2010, p. 359).

Nessa região, os Brandalise deram início às atividades com o moinho de trigo e investiram em um lote no centro comercial da Vila Perdizes, além da construção de um espaço para a colocação de um armazém “de secos e molhados”. Este armazém acabou se transformando em ponto de encontro para grupos de italianos, sendo administrado pelo filho mais velho do casal Brandalise, André David, a partir de 1926. Segundo Tassara e Scapin (1996) enquanto o moinho de trigo da família crescia, a seu lado foi construído um galpão para o pernoite dos peões. Com a chegada de engrenagens mais modernas foi possível realizar ao mesmo tempo a moagem do trigo e o beneficiamento de arroz, sendo esta última atividade uma grande novidade para aquela época.

A Perdigão foi fundada em 1934, no Extremo Oeste de Santa Catarina (Brasil), pelas famílias Ponzoni e Brandalise. Segundo Tassara e Scapin (1996) tornaram-se sócios da Ponzoni, Brandalise \& Cia, Angelo e Pedro Ponzoni com 37.5\% do capital e André David, Arthur, Guilherme, Abraão e Saul Brandalise com 62.5\%. Aliás, sobre o controle societário da Perdigão em sua primeira fase de crescimento (ver quadro 2). 


\section{QUADRO 2. DIVISÃO ACIONÁRIA DA PERDIGÃO NA PRIMEIRA FASE DE CONTROLE ADMINISTRATIVO}

\begin{tabular}{ll}
\hline Controle acionário & \multicolumn{1}{c}{ Cargo } \\
\hline Saul Brandalise & Diretor superintendente \\
Antonio Pasqualli & Diretor comercial \\
André David Brandalise & Diretor comercial \\
Achyles Emílio Ponzoni & Diretor gerente \\
Euclides Anastácio Brandalise & Diretor tesoureiro \\
Luis Kellermann & Diretor industrial \\
Pedro Ponzoni & Diretor assistente \\
Giácomo Pasqualli, Angelo Ponzoni e Orlando Zardo & Demais cargos de diretoria \\
\hline
\end{tabular}

Fonte: BRF (2009).

Em 1939, a Ponzoni, Brandalise Cia. Ltda associou-se à Frey \& Kallermann para iniciar suas atividades num abatedouro de suínos ${ }^{4}$ (ver quadro 3). A banha de porco e os produtos defumados e embutidos produzidos pelo Frigorífico Frey \& Kallermann eram comercializados em um posto de vendas de produtos suínos na localidade de Vila Vitória, atendendo um mercado consumidor em ascensão devido à expansão das áreas colonizadas pelo processo de imigração.

As atividades foram estabelecidas conforme o grau de especialização dos seus sócios proprietários, ou seja, enquanto os italianos eram responsáveis pela comercialização da matéria-prima e produtos, os alemães responsabilizavam-se pela produção. Logo adiante, tanto a Sociedade da Banha Catarinense, quanto o abatedouro e o Posto de Vendas da Vila Vitória acabaram sendo absorvidos pela Ponzoni, Brandalise \& Cia. e a sociedade com a Frey \& Kallermann foi desfeita (Tassara e Scapin, 1996).

A partir deste momento, as famílias Ponzoni e Brandalise esperavam que sua entrada no ramo de industrialização e comercialização fosse definitiva. Em 1940, aproveitando a produtividade de uma terra fértil, o cultivo dos parreirais iniciados ainda nas primeiras épocas de colonização e a grande quantidade de uvas colhidas na região, a Ponzoni, Brandalise \& Cia. diversificou suas atividades investindo no setor de vinhos, constituindo a Sociedade de Vinhos Catarinenses Ltda. Para ampliar a capacidade produtiva deste produto, adotou uma estratégia de verticalização ao adquirir $15000 \mathrm{~m}^{2}$ de terra que pertencia a Fritz Lorenz.

Em 1941, o nome Perdigão foi escolhido para representar os produtos da Sociedade da Banha Catarinense Ltda. (banhas, salames, presuntos, linguiças, salsichas, carnes defumadas e salgadas). O Jornal Tribuna, do município de Cruzeiro, anunciou em 1942 que todos os produtos que traziam a marca Perdigão eram símbolo de garantia e de boa qualidade (Tassara e Scapin, 1996). Neste período, o frigorífico já abatia cerca de 80 animais por dia e estratégias de verticalização foram adotadas criando melhorias em infraestrutura, construindo instalações para estocagem de lenha, cercados para concentração de animais antes do abate, instalação de postos de compra e venda em locais estratégicos e o estabelecimento de uma granja para criação e engorda de suínos, entre outros animais (BRF, 2009). Assim, em meados de 1940 a empresa diversificou seus produtos

${ }^{4}$ Em 1939, a Frey \& Kallermann e a Ponzoni, Brandalise \& Cia se associam para criar a Sociedade da Banha Catarinense Ltda-Fábrica de Produtos Suínos \& Cia. (Tassara e Scapin, 1996). 


\section{QUADRO 3. GARACTERÍSTICAS E AS ESTRATÉGIAS PARA A AMPLIAÇÃO DOS NEGÓCIOS DO GRUPO PERDIGÃO ENTRE AS DÉCADAS (1930 E 1950)}

\begin{tabular}{lll}
\hline Ano & \multicolumn{1}{c}{ Empresa } & \multicolumn{1}{c}{ Atividade } \\
\hline 1934 & Ponzoni, Brandalise e Cia. & Comércio de “secos e molhados” \\
1937 & Ponzoni, Bonato e Cia. & Comércio em geral \\
1939 & Sociedade de Banha Catarinense & Fábrica de produtos suínos \\
1940 & Sociedade de Vinhos Catarinense & Vinho e outros derivados de uva \\
1943 & Sociedade Curtume Catarinense & Industrialização de couros e peles \\
1947 & Ponzoni, Brandalise e Cia. & Serraria e fábrica de caixas \\
1955 & Expresso Perdigão & Transporte de mercadorias \\
1957 & Transporte Aéreo & Transporte de produtos perecíveis \\
& & Mudança da Razão Social da a Ponzoni \\
1958 & Perdigão S. A. Comércio e Indústria & Brandalise, S. A. \\
\hline
\end{tabular}

Fontes: elaboração própria com base em Dalla Costa (2007) e BRF (2009).

e conseguiu ser reconhecida como exportadora de banha, embutidos, cereais e frutas. Em 1945, a Ponzoni, Brandalise Cia Ltda. passou a denominar-se Ponzoni Brandalise, S. A.: Comércio e Indústria.

A expansão dos negócios da Ponzoni Brandalise, S. A. continuou com a compra de terras em áreas de reservas florestais onde se encontravam grande quantidade de madeiras nobres. Completavase desta forma outras etapas dos processos de verticalização na cadeia produtiva, pois com a extração da madeira e as instalações de serrarias, a Ponzoni Brandalise, S. A. adotou estratégias de verticalização-diversificação de atividades e produtos aproveitando o excedente de madeiras de suas serrarias para comercializá-las como tábuas de construção ou ainda como caixas para frigoríficos, embalagens para os produtos manufaturados, engradados e caixas para hortifrutigranjeiros (BRF, 2009).

Um ponto importante em relação às estratégias de consolidação do grupo é o que se refere à logística de transportes. Com o crescimento do frigorífico e a capacidade de abate e processamento era preciso encontrar uma forma mais eficiente de transportar os suínos até os mangueirões que ficavam nas proximidades do frigorifico às margens do Rio do Peixe.

A solução dos irmãos André David, Arthur e Saul Brandalise e seus sócios Angelo, Pedro e Achyles Ponzoni no início dos anos 1950 foi construir uma ponte de madeira sobre o Rio das Pedras. No entanto, havia um problema maior para ser resolvido em termos logísticos: transportar os produtos alimentícios perecíveis (linguiça fresca, salame, presunto cozido, lombo, carnes salgadas, carnes defumadas e a banha Perdigão) para o grande centro consumidor de São Paulo. Os pequenos caminhões -Expresso Perdigão- sem um sistema de refrigeração, onde a carga era protegida apenas por lonas térmicas, rodavam mais de 1000 quilômetros em estradas sem infraestrutura e durante 24 horas ininterruptas. As duplas de motoristas de 20 caminhões revezavam-se ao volante sem ter descansos nos finais de semana e feriados e a carga, perecível, sempre corria o risco de não chegar em boas condições nas mãos dos consumidores cada vez mais exigentes (BRF, 2009). 
Para reduzir as perdas, era preciso diminuir o tempo de viagem. Isso só foi possível devido à adoção do modal aéreo como meio de transporte. A partir da integração vertical a Perdigão adquiriu dois aviões Douglas DC-3 com capacidade de 3000 quilos de carga cada que, em pouco mais de duas horas de voo, transportavam os produtos de Videira para São Paulo mantendo a qualidade desejada (BRF, 2009). Além disso, os DC-3 foram fundamentais para dar maior agilidade e eficiência no intercâmbio comercial entre o Sul do Brasil e os centros urbanos. Também diminuíram os riscos existentes sobre o processo importação de matrizes de suínos e aves, fundamentais ao aprimoramento e à melhoria técnica dos produtos da Perdigão (Tassara e Scapin, 1996). Os caminhões, no entanto, não foram desativados, pelo contrário, com a modernização das estradas a partir da segunda metade da década de 1950 e o advento das câmaras frigoríficas, os modais rodoviários proporcionaram um menor custo de transporte, substituindo os velhos DC-3 que foram desativados ou vendidos (BRF, 2009).

Em 1954 a Ponzoni Brandalise, S. A.: Comércio e Indústria mudou sua razão social para Ponzoni Brandalise, S. A.: Comércio, Indústria e Transportes. Em plena fase de expansão de negócios, a empresa preocupou-se com o aprimoramento da criação de aves e suínos. A partir da segunda metade da década de 1950, a Perdigão deu início a um projeto para o melhoramento genético na suinocultura. Para tanto, importou da Europa e EUA matrizes das raças Duroc Jersey (EUA), Landrace (Suécia), Berchshire Wessex, Sadblack e Hampshire (Inglaterra) (bRF, 2009). O projeto ainda incluía no interior da Granja Santa Gema, a construção de uma pequena maternidade com doze baias para fêmeas em gestação e seus leitões.

No mesmo período a empresa começou a produzir rações balanceadas, concentrados e suplementos alimentares em uma fábrica construída nas imediações do frigorífico. Integravam-se, dessa forma, as atividades relacionadas ao processamento de suínos e ao moinho de trigo. A avicultura ganhou novos investimentos a partir da construção de aviários, no cuidado com as matrizes, com produção de ovos e na criação de aves para ao abate.

Através de estratégias baseadas nos processos de integração vertical e diversificação de atividades e produtos, a Ponzoni Brandalise S. A. conseguiu expandir seus negócios. No final dos anos 1950 se transformou em um complexo de empresas, interrelacionando seus empreendimentos dentro de um mesmo sistema produtivo: granja, abatedouro, fábrica de banha, curtume, moinho, fábrica de rações, madeireira, fábrica de caixas, entrepostos de vendas, postos de vendas de produtos finais, depósitos, lojas e filiais em São Paulo e Rio de Janeiro; além da participação acionária em outras empresas e empreendimentos nas cidades de Tangará, Videira e Curitiba.

Em 1958, a Ponzoni Brandalise, S. A.: Comércio, Indústria e Transportes alterou sua razão social para Perdigão, S. A. Comércio e Indústria. Segundo Tassara e Scapin (1996, p. 68), o capital social da empresa estava subdividido em “58.400 ações ordinárias e 4000 ações preferenciais nominativas". O controle acionário e a direção da Perdigão estavam praticamente nas mãos da família Brandalise, enquanto os Ponzoni vinham diminuindo sua participação acionária, mantendo ocupados alguns postos de diretoria.

\section{Características e estratégias do grupo Perdigão entre as décadas de 1960 e 1980}

Entre as décadas de 1960 e 1980, a Perdigão cresceu diversificando produtos e atividades e expandindo seus negócios, principalmente, no município sede de Videira-SC. Entre a metade da década 1970 e durante os anos 1980, a Perdigão optou por estratégias que lhe permitiram atuar em outros ramos de atividade e promover sua expansão territorial. No entanto, estes investimentos 


\section{QUADRO 4. SEGUNDA FASE DE CONTROLE ADMINISTRATIVO DA PERDIGÃO (DÉCADAS 1960 A 1980)}

\begin{tabular}{|c|c|}
\hline Controle Acionário & Cargo \\
\hline Saul Brandalise & Presidente executivo \\
\hline \multicolumn{2}{|c|}{1974} \\
\hline André David Brandalise & Auxiliares do presidente executivo \\
\hline Flávio Brandalise e Saul Brandalise Jr. & Auxiliares do presidente executivo \\
\hline Achyles Emílio Ponzoni & Auxiliares do presidente executivo \\
\hline Luis Gabriel e Angelo Leoni & Auxiliares do presidente executivo \\
\hline \multicolumn{2}{|c|}{1976} \\
\hline Flávio Brandalise & Presidente executivo \\
\hline \multicolumn{2}{|c|}{1978} \\
\hline Saul Brandalise Jr. & Presidente executivo \\
\hline \multicolumn{2}{|c|}{1987} \\
\hline Saul Brandalise & Presidente do cons. administrativo \\
\hline Flávio Brandalise & Presidente do Grupo Perdigão \\
\hline \multicolumn{2}{|c|}{1989} \\
\hline \multicolumn{2}{|c|}{ Reestruturação administrativa } \\
\hline Saul Brandalise Jr. & Diretor e vice-presidente \\
\hline Ivan Bonato & Vice-presidente executivo \\
\hline
\end{tabular}

Fontes: elaboração própria com base em Perdigão (anos 1974-1987) e BRF (2009).

geraram fortes dívidas que, nas palavras de Tassara e Scapin (1996, p. 109) geraram um complexo industrial "híbrido, desvirtuado de sua verdadeira vocação como empresa do ramo agroindustrial e frigorífico, disperso e com firmas atuando em atividades muito diferentes e sediadas em pontos tão distantes entre si, como o Mato Grosso e o Rio Grande do Sul”.

Em meados da década de 1980, a família Brandalise promoveu a primeira etapa do processo de profissionalização da Perdigão. Pressionados por acionistas minoritários, os organizadores da primeira etapa de profissionalização da Perdigão deram início a um programa de reestruturação que incluía cortes de despesas administrativas (pessoal e burocracia), reestruturação das atividades industriais e comerciais, venda de ativos não operacionais (tais como imóveis urbanos, terrenos, fazendas de reflorestamento, plantações de frutas) e de outras unidades produtivas que se distanciavam de sua atividade principal (Dalla Costa, 2007).

O fato é que apesar do empenho de Saul Brandalise, Ivan Bonato, Flávio e Saul Brandalise Jr., as dificuldades cresceram em decorrência das dívidas assumidas para a realização das atividades de expansão. A impossibilidade de honrar os compromissos financeiros assumidos, principalmente, em relação aos juros cobrados pelos bancos e demais credores tornou-se evidente, além da clara falta de confiança por parte do mercado em relação à viabilidade dos negócios.

A apresentação estabelecida no quadro 4 entre as décadas de 1960 e 1980, permite que se observe como ocorreu a redistribuição de cargos, definindo assim a mudança da primeira, para a segunda fase de controle administrativo do grupo Perdigão. 
O Quadro 5 apresenta os resultados em termos de expansão da Perdigão a partir das estratégias adotadas entre os anos 1960 e 1980. Entre as estratégias mais importantes está aquela que permitiu o desenvolvimento de um processo de integração e parceira com pequenos produtores rurais. A ideia que surgiu nos EUA foi adaptada tanto à dinâmica produtiva da Perdigão, quanto aos objetivos dos seus parceiros produtores. Diferente da estratégia tradicional estabelecida, onde a empresa vendia os pintinhos gerados na Granja Santa Gema aos produtores, a Perdigão passou a oferecer os pintinhos aos produtores rurais, que por sua vez, teriam a tarefa de acomodá-los em suas propriedades para a engorda. Para a Perdigão a integração significava a expansão dos negócios ligados à avicultura e para os pequenos produtores significava uma fonte de emprego e renda.

QUADRO 5. CARACTERÍSTICAS E ESTRATÉGIAS PARA A AMPLIAÇÃO DOS NEGÓGIOS DO GRUPO PERDIGÃO ENTRE AS DÉGADAS (1960 E 1980)

\begin{tabular}{lll}
\hline Ano & \multicolumn{1}{c}{ Empresa } & \multicolumn{1}{c}{ Atividade } \\
\hline 1962 & Perdigão, S. A. & Abate e industrialização de frangos \\
1965 & Perdigão Serviços Ltda. & Gráfica e serviços em geral \\
1968 & Filiais Comerciais & Comercialização de produtos Perdigão \\
1971 & Empório de Couros & Industrialização de couros e peles \\
1972 & Sociedade Recr. e Esp. Perdigão & Lazer para os funcionários \\
1973 & Supermercado Perdigão & Vendas a Varejo \\
1973 & San Raphael Palace Hotel & Serviços de hotelaria \\
1974 & Perdigão Alimentos, S. A. & Produção de ração, farelos e óleo de soja \\
1975 & Abatedouro Exclusivo para Aves & Abate e industrialização de aves \\
1977 & Frigorífico Unifrico, S. A. & Abate e industrialização de aves e suínos \\
1979 & Armazéns Medianeira & Atividades de armazenagem \\
1979 & Fábrica de Rações & Produção de rações para aves e suínos \\
1979 & Nodarisa Empreend. Florestais & Cultivo de maçãs \\
1980 & Perdigão, S. A. Com. e Indústria & Lançamento de ações na Bolsa de Valores Brasileira \\
1980 & Agropecuário Confiança & Atividades agropecuárias \\
1980 & Indústrias Reunidas Ouro & Abate e industrialização de aves e suínos \\
1982 & Perdigão, S. A. Com. e Indústria & Lançamento do produto “Chester" \\
1984 & Frigorífico Canta Galo & Abate de aves \\
1985 & Coop. Tritícola Taperense & Compra de cereais \\
1985 & Grupo Borella & Abate e industrialização de aves e suínos \\
1986 & Frigorífico Planalto & Abate e processamento de bovinos \\
1988 & Sulinos Alimentos & Abate de aves \\
1989 & Perdigão, S. A. & Abate e industrialização de aves \\
1989 & Swift Alimentos & Vegetais e carnes enlatadas \\
1989 & Frigorífico Mococa, S. A. & Incubatório e abate de frangos \\
1989 & Joint-venture com a Mitsubishi & Exportação de frango para o Japão \\
\hline & &
\end{tabular}

Fontes: elaboração própria com base en Perdigão (anos 1970-1989); Dalla Costa (2007) e BRF (2009). 
Para modernizar seu processo produtivo a Perdigão instalou suas unidades operacionais, laboratórios de análises químicas e microbiológicas, os quais se transformaram em pequenos núcleos de pesquisas e marcaram o princípio do acompanhamento técnico na produção. Segundo Tassara e Scapin (1996, p. 74) "mesmo que de forma muito lenta e gradual e ainda que dotados de parcos recursos, nasciam, ali, os primeiros embriões dos Departamentos de Controle de Qualidade e de Desenvolvimento de Produtos, tão fundamentais ao futuro da empresa”.

O processo de integração e parceria entre a Perdigão e os produtores locais encontrou mais resistência em relação aos suínos do que em relação às aves. A produção de suínos baseava-se na criação do chamado porco tipo banha, alimentados com abóbora, milho e pasto, como recomendavam os costumes adquiridos através de vínculos socioculturais. No entanto, a Perdigão pretendia convencer os produtores a substituírem o porco tipo banha pelo porco tipo carne que eram animais que necessitavam de maiores cuidados em relação à alimentação e ao processo de criação, mas que seriam adequados para satisfazer as necessidades de consumo.

Na década de 1970 a população brasileira quase chegou a 70000000 (Instituto Brasileiro de Geografía e Estatística, 2000). Naquela época, o país vivia os efeitos do milagre econômico, com investimentos em grandes obras de infraestrutura, com recursos financeiros disponibilizados por fontes externas e pelas facilidades de crédito e incentivos fiscais promovidos pelos governos estaduais e o governo federal. Conforme o Brasil crescia, as empresas buscavam investimentos cada vez mais altos para desenvolver grandes negócios.

Neste período, a Perdigão cresceu sob a gestão familiar e diversificou ainda mais suas atividades e produtos, rompeu fronteiras e expandiu seus negócios já pensando em internacionalizar suas operações. Foi assim que no início da década a Perdigão construiu um moderno edifício no centro de Videira-SC - as Lojas Perdigão e inaugurou as novas instalações do Empório de Couros, S. A. Com isso, o respectivo município passou a receber um número cada vez maior de clientes, fornecedores, técnicos, nacionais e estrangeiros, os quais demandavam melhores acomodações, o que levou a Perdigão a inaugurar um supermercado e um hotel no município, o São Raphael Palace Hotel, o que por sua vez, pode ser entendido como estratégias empresariais baseadas no processo de diversificação não relacionada.

Na metade da década a cadeia produtiva da Perdigão foi reforçada pela produção de soja e derivados. Nas cidades de Videira-SC e Marau-RS foram instaladas unidades processadoras desse produto, o qual era destinado à produção de rações, que por sua vez, era entregue aos produtores parceiros envolvidos com as criações de aves e suínos, além de ser comercializada com outros produtores locais. Os avanços conquistados em relação ao sistema de integração permitiram a Perdigão promover novos empreendimentos no setor de aves e suínos. Entre 1971 e 1975 deu início às atividades com congelamento de frangos e inaugurou em Videira-SC o seu primeiro abatedouro exclusivo de aves (BRF, 2009). De posse de mais duas granjas, a Liberata em FraiburgoSC e Rio das Pedras em Videira-SC organizaram o sistema de produção de pintinhos, assim como o fornecimento de ovos para o incubatório de Rio das Pedras.

Em relação à suinocultura, houve a construção de novas instalações para o desenvolvimento de raças, criação de animais e para as pesquisas sobre a elaboração de rações balanceadas destinadas à engorda e crescimento. Ao adquirir ainda no início dos anos 1970 equipamentos europeus e norte-americanos como estufas, embutideiras, custers, misturadores, injetoras, linhas de abate e de embutidos, a Perdigão adaptou seu processo produtivo aos novos equipamentos e os resultados logo apareceram com a redução do número de mercadorias rejeitadas, aumento dos prazos de validade dos produtos perecíveis e maior diversificação de produtos. 
Foi também na segunda metade da década de 1970 que a Perdigão deu os primeiros passos rumo à internacionalização. Em 1975, ao fazer parte da União dos Exportadores de Frango, conseguiu fechar o primeiro contrato de exportação para o Oriente Médio. Em pouco tempo, países como a Arábia Saudita, Kwait, Líbia, Egito, Síria, Iraque, entre outros, passaram a ser o destino dos produtos à base de frango da Perdigão. No mesmo período, além da carne de frango a firma também exportava carnes suínas, couros, farelo e óleo de soja.

Em 1977, a Perdigão viveu um momento histórico ao adquirir o controle acionário da União Velosense de Frigorífico or Unifrico, S. A., a qual foi fundada em 1963, em Salto Veloso-SC. Com isso fez sua primeira aquisição fora de Videira-SC.

Em 1979, a Perdigão enviou aos EUA dois de seus principais técnicos em avicultura: Mário Ricciardi e Edésio Jacó Brandalise. Segundo Tassara e Scapin (1996), o objetivo era procurar duas novas linhagens de avós, uma de frango de corte e uma de perus. Nos EUA, os técnicos compraram um pacote tecnológico que possibilitava reproduzir estas aves no Brasil e desenvolver uma nova matriz. Ao obter as linhas puras de frango de corte, a Perdigão instalou a Granja Avícola do Passo da Felicidade em Tangará, a qual foi preparada tecnologicamente para iniciar o Germoplasma do Chester. Assim, durante três anos, a partir de sucessivos cruzamentos entre onze linhagens diferentes de aves a perdigão conseguiu formar uma ave híbrida, praticamente constituída de carnes nobres, com cerca de 70\% de peso localizado nas coxas e no peito (BRF, 2009). O nome Chester, derivado da palavra chest, que em inglês significa peito, se tornou marca registrada da Perdigão. ${ }^{5}$

A perdigão chegou aos anos 1980 com os sistemas de integração na avicultura e suinocultura consolidados. Neste mesmo período, o grupo ainda investiu na aquisição de outras empresas, tanto no Sul, como nas demais regiões do território nacional, ampliando assim os seus negócios. As instabilidades que comprometeram o crescimento da economia brasileira na década de 1980 não impediram que a Perdigão expandisse e diversificasse seus negócios. O principal objetivo de seus administradores era fazer com que a empresa crescesse, aumentando cada vez mais sua participação no mercado, diversificando produtos e consagrando novas marcas associadas à Perdigão.

Assim, mais um passo foi dado em direção ao mercado internacional. Em 1989, ocorreu a associação industrial e comercial -joint venture- com um frigorífico de Portugal, o Persuínos. O objetivo principal dessa estratégia era o de abrir as portas da Perdigão na Europa em virtude da abertura do Mercado Comum Europeu, ao qual Portugal seria incorporado alguns anos depois ${ }^{6}$ (Tassara e Scapin, 1996). Ainda em 1989, a Perdigão efetivou uma parceria com o grupo Mitsubishi do Japão. Ao injetar recursos financeiros e tecnológicos necessários à produção de cortes especiais de aves, a Mitsubishi ajudava a Perdigão a atender o mercado daquele país. Neste contexto, a unidade de Capinzal-SC passou a ser preparada para atender esse mercado consumidor.

Em termos financeiros, ao final desse período, observou-se que entre os benefícios conquistados e as fragilidades expostas a partir da adoção de estratégias que desviaram a Perdigão de suas atividades tradicionais, ela conseguiu empregar 16000 trabalhadores, se transformando em um importante grupo econômico brasileiro, cujo faturamento chegou a 510000000 dólares per ano (Pergidão, anos 1980-1990).

${ }^{5}$ Lançado em 1982, o Chester conseguiu rápida penetração no mercado nacional, além de ser reconhecido internacionalmente.

${ }^{6}$ As dificuldades de adaptação e gestão (diferenças de hábitos e costumes alimentares da população do país até a postergação da entrada de Portugal no Mercado Comum) foram pouco a pouco desfazendo as expectativas por parte da Perdigão do Brasil. Dessa forma, a sociedade foi desfeita em 1991. 
Características e as estratégias do grupo Perdigão entre as décadas de 1990 e 2000

No início dos anos 1990, sob a orientação de uma gestão profissionalizada o grupo Perdigão buscou conciliar as estratégias de crescimento com a sustentabilidade financeira empresarial (ver quadro 6).

\section{QUADRO 6. TERCEIRA FASE DE CONTROLE ADMINISTRATIVO DA PERDIGÃO (DÉCADAS 1990 A 2000)}

\begin{tabular}{lc}
\hline \multicolumn{2}{c}{1993} \\
\hline Um acordo entre acionistas nomeou como presidente do Conselho Administrativo \\
Eggon João da Silva (fundador e presidente da Weg Motores). Lembrando que a \\
Weg já era detentora de certo volume de ações da Perdigão desde 1986. \\
\multicolumn{2}{c}{ Saul Brandalise } \\
Jr. Ivan Bonato & Diretor e vice-presidente \\
& Vice-presidente executivo \\
\hline (Transição e Controle Acionário da Perdigão)(Somando-se as ações ordinárias e \\
preferências, ficou assim distribuído o controle acionário da empresa) \\
Transição & Porcentaje \\
Previ-caixa Previdenciária do Banco do Brasil & 15.03 \\
Fundação Telebras de Seguridade Social-Sistel & 15.03 \\
Fundação Petrobras de Seguridade Social-Petrus & 12.17 \\
Real Grandeza Fundação de APAS & 9.74 \\
Weg Motores Ltda. & 8.80 \\
União de Comércio e Participações Ltda. & 3.88 \\
Previ-Banerj & 2.80 \\
BNDES-Participações, S. A. & 2.01 \\
Fundação vale do Rio Doce, VALIA & 1.73 \\
Fundação Embratel de Seguridade Social & 1.57 \\
Bradesco Turismo, S. A. & 1.12 \\
Fundo de Participação Social & 0.35 \\
Banco Bradesco & 0.10 \\
Outros & 25.67 \\
Nildemar Secches & \\
\hline
\end{tabular}

Fonte: elaboração própria com base em Perdigão (anos 1993-2000).

Na medida em que ia se consolidando a segunda etapa de profissionalização da Perdigão, os controladores buscaram contratar um profissional de mercado que, primeiramente, assumiria a diretoria financeira e, logo em seguida, a presidência do grupo.

Era perceptível o fato de que até a metade dos anos 1990 as dificuldades financeiras foram aumentando, dando a sensação de que a solução para os problemas vigentes passava pela transferência do controle acionário da empresa. Em setembro de 1994, a família Brandalise vendeu as ações da Perdigão e se afastou definitivamente. A transferência do controle acionário foi concreti- 
zada em setembro de 1994 envolvendo o Banco Icatu que apresentou uma proposta feita por um pool formado por fundos de pensão. Segundo Tassara e Scapin (1996), a negociação rendeu um capital de 150000000 de dólares, que por sua vez, representava 70.6\% do capital votante; recurso este que a família Brandalise utilizou para saldar suas dívidas com a própria empresa e os demais acionistas.

O pool de fundos de pensão elegeu um novo Conselho de Administração e um Conselho Fiscal e alterou os estatutos da empresa optando pela contratação de uma firma internacional de consultoria para selecionar um executivo capaz de conduzir seus negócios (Tassara e Scapin, 1996).

Em janeiro de 1995, ao término da fase de transição assumiu como diretor presidente da Perdigão o engenheiro Nildemar Secches, o qual daria sequência a um processo de reestruturação baseado na modernização administrativa, racionalização das operações e cortes profundos. Nesse sentido, é importante ressaltar que apesar dos fundos de pensão serem configurados como entidades privadas, sem fins lucrativos, eles administraram bilhões de reais em ativos públicos. Ou seja, havia dinheiro público em jogo, eis que as estatais, entidades da administração pública indireta, algumas das quais sustentadas diretamente pelos orçamentos gerais da União, aportavam recursos nos referidos fundos e tais recursos não se transmudavam para natureza privada pela sua inversão no patrimônio das referidas entidades (Anderson, 2012).

Em termos estratégicos, a gestão profissional da Perdigão no período, buscou então dar sequência à manutenção e ao aperfeiçoamento contínuo da qualidade dos produtos comercializados, além de procurar manter a transparência perante suas decisões de investimentos afim de atender as expectativas de seus acionistas, fornecedores e consumidores, inseridos em um mercado cada vez mais exigente (ver quadro 7).

Em relação a esses resultados, se deve destacar que a gestão de Nildemar Secches buscou adequar o sistema produtivo a uma economia globalizada e as novas exigências estabelecidas pela legislação ambiental. Entre os projetos de otimização das unidades empresariais estavam a expansão do parque agropecuário e a modernização (adequações tecnológicas) das unidades industriais de abate e processamento de carnes. O principal objetivo desse projeto era aumentar em $50 \%$ a capacidade de produção (Pergidão, anos 1996-2000). Durante este processo, algumas unidades empresariais destacaram-se, entre elas a unidade de Capinzal-SC, local de realização do projeto Chester que foi beneficiada com vários investimentos, passando a ser a sede da maior unidade de abate, com capacidade para 356000 aves-dia e geradora de 800 novos empregos diretos, além de incorporar ao processo produtivo que promoveu 400 novos produtores integrados (Pergidão, anos 1996-2000; BRF, 2009). Em Catanduvas-SC, a Perdigão estabeleceu uma nova granja de matrizes, com capacidade de 360000 aves, uma fábrica de ração que produzia 40000 toneladas por mês e, em Herval D’Oeste-SC um incubatório com capacidade para 5000000 de ovos por mês (BRF, 2009).

Em 1995, em meio a execução da primeira etapa do planejamento estratégico elaborado pela gestão profissional, a empresa voltou a operar no mercado financeiro por meio de uma operação de trocas de ações baseada nos ativos patrimoniais das empresas. Os acionistas minoritários da Perdigão Agroindustrial e da Perdigão Alimentos migraram para a Perdigão, S. A., a única que manteve capital aberto (Tassara e Scapin, 1996). A empresa procurou manter os acionistas bem informados, divulgando os resultados dos balanços. Preocupados com os lucros, os investidores, por sua vez, acompanhavam a projeção dos relatórios trimestrais e anuais, assim como a diminuição de custos administrativos e a redução do número de acionistas. 


\section{QUADRO 7. GARACTERÍSTICAS E ESTRATÉGIAS PARA A AMPLIAÇÃO DOS NEGÓGIOS DO GRUPO PERDIGÃO ENTRE AS DÉGADAS (1990 E 2000)}

\begin{tabular}{|c|c|c|}
\hline Ano & Negócios do grupo Perdigão & Características e Estratégias \\
\hline 1995 & Perdigão, S. A. & Fábrica de industrializados de suínos. \\
\hline 1998 & Complexo Agroindustrial & Abatedouro e fábrica de embutidos. \\
\hline 2000 & Frigorífica Batávia & Abate e industrialização de perus. \\
\hline 2000 & $\begin{array}{l}\text { Complexo agroindustrial } \\
\text { de Rio Verde }\end{array}$ & $\begin{array}{l}\text { Abate e o processamento de suínos e aves. } \\
\text { Ações na Bolsa de Nova York. American }\end{array}$ \\
\hline 2000 & Perdigão, S. A. & Depositary Receipt de nível II. \\
\hline 2001 & Perdigão, S. A., e Sadia, S. A. & Criação da brf Trading. \\
\hline 2001 & $\begin{array}{l}\text { Centro de Distribuição } \\
\text { de Campinas }\end{array}$ & $\begin{array}{l}\text { Armazenamento de produtos refrigerados } \\
\text { e congelados. }\end{array}$ \\
\hline 2002 & $\begin{array}{l}\text { Escritório de representação } \\
\text { de Londres }\end{array}$ & Transformação em uma unidade de negócios. \\
\hline 2002 & Fábrica de Rações de Gaurama (RS) & Reativação da produção (350 toneladas por dia). \\
\hline 2004 & Incubatório de Marau (RS) & $\begin{array}{l}\text { Capacidade de } 1000000 \text { de ovos por semana } \\
\text { Inaugurarão do Centro de Logística e }\end{array}$ \\
\hline 2004 & Perdigão, S. A. & Distribuição Curitiba. \\
\hline 2005 & Unidade do DF & $\begin{array}{l}\text { Fabricação de produtos cozidos à base de carne } \\
\text { de frango, peru e bovino para exportação. }\end{array}$ \\
\hline 2005 & Perdigão, S. A. & $\begin{array}{l}\text { Centro de Serviços Perdigão em Itajaí-SC. } \\
\text { Ampliação do Centro de Distribuição em }\end{array}$ \\
\hline 2005 & Perdigão, S. A. & Videira-SC. \\
\hline 2005 & $\begin{array}{l}\text { Abatedouro Mary Loise } \\
\text { Indústria de Alimentos } \\
\text { Centro de Distribuição de }\end{array}$ & Aquisição do controle integral do abatedouro. \\
\hline 2005 & Marau-RS & $\begin{array}{l}\text { Início das operações de logística. } \\
51 \% \text { das ações da Batávia, entrada no mercado }\end{array}$ \\
\hline 2006 & Perdigão, S. A. & de lácteos. \\
\hline 2006 & $\begin{array}{l}\text { Perdigão, S. A. } \\
\text { Complexo Agroindustrial de }\end{array}$ & Inauguração de Incubatório em Castro-PR. \\
\hline 2007 & Mineiros (GO) & Produção de aves. \\
\hline 2007 & $\begin{array}{l}\text { Sino dos Alpes Alimentos Ltda } \\
\text { Frigorífico de bovinos em }\end{array}$ & $\begin{array}{l}\text { Fábrica de produtos à base de carne suína e } \\
\text { de frango. }\end{array}$ \\
\hline 2007 & Mirassol D’Oeste (MT) & Abate de bovino. \\
\hline 2007 & Joint-venture (UP Alimentos) & Gestão das marcas Becel e Becel ProActiv. \\
\hline 2007 & Paraíso Agroindustrial, S. A. & $\begin{array}{l}\text { Frigorífico de aves e uma fábrica de rações. } \\
\text { Compra do restante das ações }(49 \%) \text {, se }\end{array}$ \\
\hline 2007 & Batávia Lácteos & tornando detentora do controle total da Batávia. \\
\hline 2008 & Perdigão, S. A. & Aquisição da Eleva. \\
\hline 2009 & Perdigão, S. A., e Sadia, S. A. & $\begin{array}{c}\text { Associação (em 2011, o Conselho Administrativo } \\
\text { de Defesa Econômica [cade] aprovou a fusão). }\end{array}$ \\
\hline
\end{tabular}

Fontes: elaboração própria com base em Perdigão (anos 1990-2008) e BRF (2009).

A segunda etapa de crescimento elaborado pela nova gestão administrativa da Perdigão esteve relacionada com a escolha de alguns municípios brasileiros para completar seus projetos de expansão. Em 1997, foi inaugurada em Marau-RS uma fábrica de ração com capacidade para 
produzir 33000 toneladas por mês (BRF, 2009). Também em 1997, foram inaugurados os Centros de Abastecimento e Distribuição de Porto Alegre-RS, Rio de Janeiro-RJ e São Paulo-SP. Este período coincide com o lançamento da linha de vegetais congelados com a marca Escolha Saudável, promovendo, além da instalação das novas unidades empresariais, a diversificação de produtos com a marca Perdigão.

O final dos anos 1990 se aproximava enquanto o grupo inaugurava a unidade de industrializados de Marau, no Rio Grande do Sul, que mais tarde passaria a produzir 122000 toneladas de industrializados de carnes de aves e suínos para o abastecimento dos mercados interno e externo (BRF, 2009). Também inaugurou os Centros de Abastecimento e Distribuição de VideiraSC, Fortaleza-CE, Cubatão-SP e Salvador-BA, além de desenvolver novos produtos investindo na modernização, o que por sua vez, foi alcançado a partir da inauguração de seu novo Centro de Tecnologia de Carnes em Videira-SC e de mais dois centros de difusão genética em Videira-SC e Rio Verde-GO.

A empresa fechou a década de 1990 promovendo a diversificação de mais produtos, lançando as massas prontas congeladas com a linha Toque de Sabor (BRF, 2009).

Os anos 2000 iniciaram com a compra de $51 \%$ do controle acionário do Frigorífico Batávia, que a Perdigão manteria como empresa independente (BRF, 2009). O investimento marcou a entrada do grupo no mercado de carnes de peru e de uma parceria na área de distribuição na América do Sul com a Parmalat. No mesmo período, enquanto era lançada a linha de pizzas prontas congeladas, o complexo agroindustrial de Rio Verde-GO entrava em fase pré-operacional com o abate e o processamento de suínos e aves.

A perdigão se destacou por ser a primeira empresa brasileira de alimentos a ter suas ações listadas na Bolsa de Nova York, lançando ADR’s de nível II. Em seguida, aderiu ao Nível I de Governança Corporativa da Bolsa de Valores de São Paulo (Bovespa), dando maior destaque aos esforços da companhia para melhorar a relação com investidores e elevar o potencial de valorização de seus ativos.

Pensando em manter uma boa relação com seus colaboradores a Perdigão resolveu conceder a seus funcionários a participação nos Lucros e Resultados. Com 20000 empregados, a Perdigão havia adquirido os 49\% restantes do controle do Frigorífico Batávia e o incorporou a Perdigão Agroindustrial, S. A., porém, manteve a marca Batavo no mercado (Perdigão, anos 2000-2009).

Em 2001, a Perdigão lançou a marca mundial Perdix, utilizada na comercialização de produtos processados. No mesmo ano, junto à Sadia, S. A., criou a Brasil Food Trading, uma empresa destinada a comercializar produtos avícolas, suinícolas e alimentos em geral produzidos por ambas as companhias, em mercados emergentes (BRF, 2009). No ano seguinte, entrou no segmento de sobremesas prontas congeladas, com o lançamento de pizzas doces e duas novas linhas de tortas e folhados ambos na versão salgada (Perdigão, 2002).

Ao final de 2002, o Chester chegou ao seu $20^{\circ}$ Natal como líder absoluto na categoria de aves especiais, enquanto a Fábrica de Rações de Gaurama-RS foi reativada em dezembro, produzindo 7000 toneladas de rações por mês (Perdigão, 2002).

O ano de 2003 iniciou com a inauguração da unidade de Rio Verde-GO, o que por sua vez, possibilitou a ampliação das linhas de sobremesas prontas a partir do lançamento versão doce dos Folhados Perdigão. Neste momento, o quadro de funcionários da empresa ultrapassou 27000 pessoas (Perdigão, 2003). 
Perdigão comemorou seu $70^{\circ}$ aniversário de fundação em 2004, decidindo manter um canal de comunicação com seus consumidores. Lançou então o programa de TV Receitas da Vida Perdigão. A empresa havia idealizado um programa em rede nacional de televisão para ouvir e falar com seus clientes e consumidores, indo ao ar nos sábados pela "Rede TV" e aos domingos pela TV Mulher. Também lançou o Chicken PopCorn (pipoca de frango), cubinhos de frango empanados e congelados, prontos para consumo. No complexo de Marau-RS, passou a concentrar sua produção de salames, copas e presunto cru. Com base no objetivo de obter ganhos de escala, investiu 6600000 de reais na construção de um novo incubatório neste município, cuja capacidade de produção era de 1000000 de ovos por semana (Perdigão, 2004).

No final de 2004, a Perdigão inaugurou o Centro de Logística e Distribuição de Curitiba. Este empreendimento resultou de um novo modelo de parceria, em que a construção das instalações e a logística eram terceirizadas, mas as condições e especificações eram estabelecidas pela Perdigão. O cento de distribuição foi construído pela Customer Relationship Management Logística, um pool de investidores paranaenses que investiu aproximadamente 12500000 de reais sendo que a firma contratada para operar o novo centro foi a Fibralog (Perdigão, 2004).

A Perdigão fechou a primeira metade da década de 2000 com uma série de eventos importantes. Em 2005, adquiriu novas unidades e ampliou seus investimentos nos mercados de carne bovina e de margarinas. Também começou a operar nos segmentos de cozidos a base de carne de bovina, frango, peru. Com o objetivo de dinamizar a exportação desses produtos, fechou um contrato de locação com a Industrial e Comercial de Alimentos, localizado em Santa Maria, no Distrito Federal. Ademais, investiu 41000000 de reais no Paraná para ampliar a capacidade produtiva de seu complexo agroindustrial em Carambeí e instalar um novo incubatório de frangos em Castro (BRF, 2009). Em Santa Catarina foi criado o Centro de Serviços Perdigão em Itajaí. Essa unidade passou a ser um instrumento de modernização e gestão, permitindo que a empresa racionalizasse seus processos e diminuísse os custos operacionais. Segundo BRF (2009), o Centro de Serviços Perdigão, cujos investimentos giraram em torno de 20000000 de reais, concentrou as atividades das áreas de finanças, controladoria, relações humanas, tecnologia da informação, apoio a vendas e suprimentos.

Enquanto isso, em Videira-SC, foi concluída a ampliação de outro centro de distribuição. Eram 4200 metros quadrados com capacidade para 5800 posições de estoques, 3900 para produtos congelados e o restante para resfriados (BRF, 2009). A Perdigão também chegaria ao Mato Grosso-MT por meio da aquisição do Abatedouro Mary Loise Indústria de Alimentos, dona da marca Dunaturalis, e da Mary Loise Indústria e Comércio de Rações. O valor destes investimentos foi de 40000000 de reais (Perdigão, 2005).

No centro de distribuição de Marau-RS começaram as operações nas instalações de 4100 metros quadrados de área construída e capacidade para 4700 posições, o equivalente a 3500 toneladas de produtos. Essa unidade também passou a realizar composições de carga para todo o Brasil e exterior (BRF, 2009). A Perdigão ainda assinaria um contrato de prestação de serviços industriais com a Arantes Alimentos Ltda. sediada em Cachoeira Alta-GO, passando a atuar no mercado de bovinos com foco voltado para a exportação.

O grupo Perdigão operou no Novo Mercado da Bovespa em 2006, adquirindo o restante dos $51 \%$ do capital social da Batávia, S. A. Indústria de Alimentos. Seu Objetivo era entrar no mercado de lácteos em parceria com a Cooperativa -Cooperativa Central de Laticínios do Paraná-, 
e Agromilk que continuaram mantendo 49\% do capital da Batávia. Neste mesmo período ocorreram as inaugurações dos incubatórios em Castro-PR e Serafina Corrêa-RS junto à implantação do Sistema de Gestão Integrada nestas regiões.

Aproximava-se o final da primeira década do século xxi e a Perdigão decidia manter sua política de expansão, diversificando operações e cumprindo etapas estabelecidas em seu planejamento estratégico, tentando assim diluir os riscos e assegurar a sustentabilidade do negócio. Ampliou sua atuação nas atividades de lácteos, margarinas e bovinos, a partir de parcerias e aquisições de ativos no Brasil e no exterior. Também inaugurou um complexo agroindustrial, em Mineiros-GO, para produção de aves, com capacidade para processar 81000 toneladas por ano de produtos à base de carne de aves, o equivalente a 24000 cabeças de peru e 140000 cabeças frango e ave Chester por dia (BRF, 2009).

Em março de 2007 diversificou produtos e atividades ao entrar no mercado de pet food. Com isso, lançou as rações para cães das marcas Balance e Supper. Os produtos foram os primeiros do portfólio da Essencial Pet Care, divisão criada especialmente para o segmento. Comprou a Sino dos Alpes Alimentos Ltda., subsidiária da Grandi Salumifici Italiani, grupo líder em embutidos na Itália. Instalada na cidade de Bom Retiro do Sul (RS), a unidade fabricava produtos à base de carne suína e de frango, entre os quais salsicha, presunto, apresuntado, linguiça, patê, fiambres e mortadela (Perdigão, 2007).

Neste momento, a Perdigão chegou a um acordo com o grupo holandês Cebeco Groep BV para aquisição da Plusfood Groep BV. Esta empresa holandesa fabricava produtos processados e de conveniência à base de carnes de aves e bovinos, e detinha duas marcas relevantes no mercado europeu: Fribo e Friki. Também foi o momento em que o grupo adquiriu o frigorífico de bovinos em Mirassol D’Oeste, no Estado do Mato Grosso. O negócio atendia as metas de ampliação de atuação na área de bovinos, estabelecidas nos planos estratégicos que se manteriam até 2011 (BRF, 2009).

Na sequência dos acontecimentos ocorreu a compra da Paraíso Agroindustrial, S. A. composta por um frigorífico de aves e de uma fábrica de rações que pertencia ao Grupo Gale de Jataí-GO e a inauguração das obras de ampliação de sua unidade em Nova Mutum-MT, elevando a capacidade diária de abates de 40000 cabeças para 280000 cabeças (Perdigão, 2007). Realizaram-se acordos com as cooperativas Agromilk, Castrolanda, Batavo e Capal, para a compra de 49\% da participação detida por elas no capital da Batávia. O valor total do negócio foi de 155000000 de reais, lembrando que a Perdigão já detinha o controle acionário da Batávia (51\%) desde meados de 2006 (Perdigão, 2007; BRF, 2009). Entre as estratégias estabelecidas para o ano de 2008, a aquisição da Eleva é, possivelmente, a que mereça maior destaque. Ao adquirir essa unidade produtiva a Perdigão aumentou sua capacidade de exportação de produtos cárneos e lácteos.

O período em questão, também coincide com as ações estratégias assumidas pela gestão profissional da Perdigão para consolidar um processo de internacionalização mais amplo, que eliminasse os intermediários e atendesse o consumidor final, reduzindo assim a dependência de venda de commodities e direcionando seus negócios para os produtos de maior valor agregado. Dentro dessa perspectiva, a Perdigão decidiu pela abertura de um escritório em Londres no ano de 2000 e outro em Dubai, nos Emirados Árabes, no ano de 2002. A iniciativa ampliou a presença de suas marcas Halal, União dos Exportadores de Frango e Borella, em países do Oriente Médio (Menezes, 2008). Ainda em 2002, a Perdigão reestruturou o atendimento ao mercado europeu e transformou o escritório de representação de Londres em uma unidade de negócios, que coordenava a unidade da Holanda (BRF, 2009). Além disso, o grupo iniciou a exportação de camarões 
congelados produzidos por terceiros, lançando a Linha Freski. Este produto reforçou a presença do grupo Perdigão no exterior e abriu o caminho para entrada no mercado norte-americano que passou a ser o maior importador mundial do produto (BRF, 2009). Já em 2004, entraram em operação escritórios de vendas em Cingapura e Tóquio, os quais ampliaram a participação da Perdigão no mercado local e fortaleceram seu projeto de internacionalização (Menezes, 2008).

Segundo Ricardo Meneses, então Diretor de Relações Institucionais da Perdigão, em 2008, o processo de internacionalização havia passado por várias fases. Antes de tudo, a primeira etapa envolveu a abertura e a consolidação de escritórios no exterior (Japão, Hong Kong, Moscou, Dubai e Holanda), os quais deixaram de ser pontos de vendas e transformaram-se em locais de desenvolvimento de novos produtos, logística e pós-vendas. Com a compra da Plusfood Groep BV, em 2007, por 31200000 de euros a empresa passou a ter três plantas de processamento de carnes em Oosterwolde (Holanda), Wrexham (Reino Unido) e Constanza (Romênia), e para garantir fatias cada vez maiores no mercado internacional, a Perdigão fez com que as marcas já consagradas do grupo fossem comercializadas em diferentes partes do mundo (Perdigão, 2007; Menezes, 2008). A Perdix, por exemplo, foi usada para facilitar a identificação dos produtos Perdigão no mercado global, além disso, a firma criou marcas que foram comercializadas em mercados específicos, a exemplo da Fazenda, destinada ao mercado russo, junto com outras marcas adotadas para a venda no mundo islâmico, cujas exigências são diferenciadas.

A Perdigão fechou o primeiro trimestre de 2008 com um faturamento bruto de 2.85 bilhões e crescimento total de $64.5 \%$ em volumes vendidos de carnes, lácteos e outros produtos processados (Perdigão, 2008). Segundo Menezes (2008), este resultado refletiu, tanto o bom desempenho registrado nos mercados interno e externo, quanto o fortalecimento das bases da companhia no Brasil e no exterior a partir da incorporação das operações da Eleva e da Plusfood. Segundo Perdigão (2008), as vendas no ano de 2008 no mercado interno somaram 1.74 bilhão, aumento de $69 \%$ ante o mesmo exercício do ano anterior, com incremento de $31 \%$ nos volumes de carnes e 197\% em produtos lácteos. As exportações atingiram 1.1 bilhão, valor 46.7\% superior em comparação ao primeiro trimestre de 2007 , refletindo o ritmo de crescimento da demanda nos principais mercados, com destaque para o Oriente Médio e o Extremo Oriente (Menezes, 2008). O lucro bruto chegou a 536400000 de reais.

Em 2009, ocorreu a promoção da marca Batavo que apresentou três versões de leite em pó: integral, integral instantâneo e desnatado instantâneo, as quais traziam em sua composição vitaminas A e D. Por intermédio da Batavo, a Perdigão também lançou as linhas de queijos em três variedades: prato, mussarela e parmesão. No mesmo ano, além do lançamento do "frango caipira inteiro congelado", cinco marcas da Perdigão nas categorias hambúrguer, mortadela, salgadinho, vegetais congelados e leite longa vida receberam o título Líderes de Vendas conferido pela Associação Brasileira de Supermercados (BRF, 2009).

Mas, o ano de 2009 também passaria a ser considerado um marco importante na história da Perdigão devido a consolidação do processo de fusão com sua principal concorrente, a Sadia, S. A. Estrategicamente, entende-se que um processo de fusão poderá promover ganhos de sinergia e eficiência (Fee e Thomas, 2004; Romano e Almeida, 2015). Por sua vez, Hosken e Simpson (1998) e Romano e Almeida (2015) apontam para quatro ganhos que os rivais podem ter com processos de fusão: a) a empresa que é concorrente se beneficia com maiores lucros, dados os preços mais altos advindos de uma fusão; $b$ ) a que é concorrente se beneficia quando uma fusão revela oportunidades de obter eficiências via fusão, que antes não conheciam; $c$ ) a concorrente se 
beneficia quando as firmas que participam do processo de fusão são forçadas a vender ativos com um desconto para satisfazer decisões antitrustes; $d$ ) a concorrente pode se beneficiar se as empresas, no processo de fusão, aumentarem o esforço de marketing.

Os dois primeiros eventos relacionados à fusão Perdigão e Sadia foram, a oferta hostil da Sadia para comprar a Perdigão em 17 de julho de 2006 e a revogação definitiva da Sadia para compra da Perdigão em 21 de julho de 2006. Após a consolidação da nova composição acionária da Perdigão, a Sadia iniciou uma tentativa de aquisição submetendo um edital de Oferta Pública de Aquisição à Comissão de Valores Mobiliários. Porém, a oferta foi rapidamente rejeitada pelo grupo dos fundos de pensão que, contando com outros acionistas não controladores, somavam $55.38 \%$ das ações da Perdigão.

O terceiro evento relacionado à fusão dos dois grupos refere-se ao julgamento de um processo contra conselheiros e diretores da Sadia. Em 2006, Luiz Gonzaga Murat e Romano Ancelmo Fontana teriam feito uso de informações privilegiadas sobre a oferta de compra da Perdigão pela Sadia para obter lucro na Bolsa de Nova York. Foi neste momento, em 2006, que a cúpula administrativa da Perdigão teve a sensação de que de que a união entre as duas nunca aconteceria (Batista, 2009).

O quarto evento relacionado à fusão ocorreu em 25 de setembro de 2008 diante dos prejuízos que a Sadia apresentou. A área financeira realizou operações de hedge, apostando na valorização da moeda brasileira em relação ao dólar norte-americano. O prejuízo com esta operação chegou a 2.5 bilhões de reais (Redação, 2011). Segundo Romano e Almeida (2015) a Sadia passou a enfrentar sérias dificuldades para recuperar as perdas decorrentes das operações financeiras malsucedidas e da má impressão deixada, tanto no mercado interno, quanto externo. Nestas condições a Sadia divulgou nota admitindo negociações com terceiros, inclusive, sobre a possibilidade de estabelecer uma associação com a Perdigão (Romano e Almeida, 2015).

O quinto evento que marca a relação entre Perdigão e Sadia ocorreu em 19 de maio de 2009, quando anunciaram o início do processo de associação. Foram cumpridas duas etapas desde a associação até a concretização do processo de fusão: na primeira, foi criada a HFF Participações, S. A., pertencente à Sadia e futuramente incorporada à Perdigão, cujo nome mudou para BRF. Na segunda, a BRF incorporou os minoritários da Sadia e os detentores de ações preferenciais das duas firmas participantes da fusão, os quais receberam em troca ações ordinárias para viabilizar a listagem no Novo Mercado da BM\&FBOVESPA. Após a fusão, ocorreu uma reorganização societária em que os sócios originais da Perdigão detiveram, na nova companhia, $68 \%$ da BRF, e os da Sadia ficaram com $32 \%$ do novo grupo (Romano e Almeida, 2015).

O sexto evento em relação fusão Perdigão e Sadia foi justamente o primeiro julgamento do Conselho Administrativo de Defesa Econômica (em diante CADE) sobre o processo de fusão. Em 8 de junho de 2011, o relatório do conselheiro do CADE, Carlos Ragazzo, havia defendido o veto à fusão entre Sadia e Perdigão alegando que a concentração de mercado da BRF geraria aumento de preços de alimentos e de inflação.

O sétimo evento foi decisivo para a fusão entre as duas empresas, ocorrendo em 13 de julho de 2011. Depois de várias reuniões, BRF e CADE selaram acordo e a fusão entre as duas foi finalmente aprovada. Aconteceu assim a união dos dois grandes grupos do setor de alimentos do Brasil, dando origem à BRF S. A. Com o acordo selado, foi suspendida a venda de produtos da marca Perdigão e Batavo. A BRF também ficou obrigada a alienar cadeias completas de produção (Romano 


\section{QUADRO 8. PARTICIPAÇÃO PERCENTUAL DE ALGUNS PRODUTOS ANTES E DEPOIS DA FUSÃO}

\begin{tabular}{lrrr}
\hline Produtos & Perdigão & Sadia & BRF \\
\hline Carnes resfriadas & 25 & 28 & 53 \\
Carnes congeladas & 34 & 36 & 70 \\
Massas & 38 & 50 & 88 \\
Pizzas semiprontas & 34 & 33 & 67 \\
Margarina & 18 & 30 & 48 \\
\hline
\end{tabular}

Fonte: BRF (2009).

e Almeida, 2015). Segundo Sereia et al. (2011), apesar da forte concorrência no mercado de produtos industrializados e pratos semiprontos, a união entre as duas companhias fortaleceu a participação no mercado (ver quadro 8).

Perdigão e Sadia possuíam características complementares. Essas características colocadas lado a lado criaram sinergias capazes de consolidar uma gigante do setor de alimentos, a Brasil Foods (BRF), deixando poucos espaços para aquisições no Brasil.

Segundo BRF (2009), nos três primeiros anos após a fusão entre Perdigão e Sadia, a BRF mostrou que a comercialização de produtos cárneos, pratos prontos e embutidos, entre outros renderam a companhia um valor de mercado duas vezes maior do que o valor gerado por Perdigão e Sadia separadamente, chegando a quase 30 bilhões.

\section{Considerações Finais}

O principal objetivo deste trabalho foi apresentar a Perdigão como uma estrutura organizacional do tipo business group consolidada no Brasil entre 1934-2009.

Os BG's são estruturas organizacionais geralmente controladas por entidades centrais como famílias, empreendedores individuais, estatais, bancos e demais instituições financeiras, além de outros grupos econômicos que passam a exercer o controle acionário. Há diferenças importantes entre essas estruturas empresariais e aquelas descritas com base no ideário de ChandlerWilliamson identificadas como (H) holdings e (M) multidivisionais, que por sua vez, representam grandes empresas formadas em economias maduras -diferentemente dos grupos de negócios diversificados que proliferaram em economias emergentes.

Estudando as organizações BG's, entendemos que fatores sistemicamente relacionados como as formas de propriedade e controle e os processos realizados por meio de escolhas estratégicas bem definidas revelam os níveis de desempenho das corporações e explicam como os grupos consolidam-se nos locais de origem. Considerou-se então que a Perdigão como uma estrutura organizacional do tipo BG', adotou estratégias importantes como parte dos planos elaborados pelas famílias fundadoras ou pela gestão profissional para a expansão dos negócios, apesar das dificulda-

des inerentes a um mercado imperfeito, repleto de tensões políticas e sociais, peculiares à economia brasileira. 
O grupo Perdigão foi gerenciado pelas famílias fundadoras, principalmente pelos Brandalise, de 1934 até meados da década de 1990. Até mesmo a transferência do controle acionário para o pool de investimentos em setembro de 1994 não descaracterizou a Perdigão como estrutura BG, já que a maioria dos investidores era formada por instituições financeiras, fundos estatais (federais e estaduais) com características associadas às estruturas do tipo BG's. Os chamados laços sociais promovidos pela Perdigão a partir de vínculos socioculturais, também mostram evidências sobre a formação de BG's por parte dessa organização empresarial. Além de estar submersa nas tradições culturais trazidas pelos imigrantes, principalmente italianos e alemães, sempre valorizou os vínculos associativos com a comunidade, observando as características sociais do mercado e indo além das decisões assumidas no ambiente empresarial.

Para financiar seus planos de expansão, a Perdigão participou do mercado financeiro promovendo a abertura de capital de três empresas na década de 1980 e, em 1995, fez com que seus acionistas minoritários migrassem para a Perdigão, S. A., a única que manteve capital aberto. Isso permitiu que o grupo Perdigão elaborasse planos de crescimento mais consistentes e exercesse o controle administrativo a partir de uma mesma entidade e com pelo menos uma empresa listada.

É comum atribuir aos BG's parte da responsabilidade pelo desenvolvimento das economias periféricas. Considerando-se essa possibilidade, é possível concluir que ao redirecionar seu capital às atividades produtivas, promover adequações tecnológicas, adotar um sistema de integração, diversificar suas atividades e criar novos produtos, sendo então capaz de expandir seus negócios em âmbito nacional e internacional, o grupo Perdigão acabou beneficiando as economias das localidades em que instalou suas unidades.

Concluímos então que a brasileira Perdigão reuniu características que a consolidaram como uma estrutura organizacional do tipo BG's, reconhecida como uma das maiores organizações empresariais do setor de alimentos do país em virtude da sua capacidade de explorar, por meio das estratégias de crescimento adotadas entre 1934 e 2009, as sinergias criadas entre as atividades complementares dos setores de carnes e derivados.

\section{REFERÊNCIAS}

Aldrighi, D., Postali, F. y Slaibe, F. (2010). Business groups in Brazil. En A. Colpan, T. Hikino y J. Lincoln (eds.), The Oxford handbook of business groups. Oxford: Oxford University Press. DOI: 10.1093/oxfordhb/9780199552863.001.0001

Almeida, H. y Wolfenzon, D. (2006). A Theory of Pyramidal Ownership and Family Business Groups. The Journal of Finance, 61(6), 2637-2680. DOI: 10.1111/j.1540-6261.2006.

01001.x

Anderson, R. (2012). Fundos de pensão das estatais. As notícias preocupam os aposentados e pensionistas da previdência complementar fechada. Revista Jus Navigandi, 17(3278). Recuperado de https://jus.com.br/artigos/22076

Barbero, M. y Puig, N. (2016). Business groups around the world: An introduction. Business History, 58(1), 6-29. DOI: 10.1080/00076791.2015.1051530

Batista, F. (2009). Após três tentativas frustradas, Sadia e Perdigão anunciam fusão. Gazeta Mercantil, B1.

Bernhoeft, R. (1989). Empresa familiar: Sucessão profissionalizada ou sobrevivência comprometida. São Paulo: Nobel. 
Brandalise, S. (1982). Retrato de um homem. Videira: Perdigão S. A. Comércio e Indústria.

Brasil Foods [BRF] (2009). Cronología. Perdigão. Recuperado de https://www.perdigao.com.br/aperdigao/

Carney, M., Gedajlovic, E. R., Heugens, P., Van Essen, M. y Van Oosterhout, J. (Hans). (2011). Business Group Affiliation, Performance, Context, and Strategy: A Meta-analysis. Academy of Management Journal, 54(3), 437-460. DOI: 10.5465/amj.2011.61967812

Chang, S. J. (2003). Ownership Structure, Expropriation, and Performance of Group-Affiliated Companies in Korea. Academy of Management Journal, 46(2), 238-253. DOI: 10.5465/30040 617

Colpan, A., Hikino, T. y Slaibe, F. (2010). Foundations of business groups: Towards na integrated framework. En A. Colpan, T. Hikino y J. Lincoln (eds.), The Oxford handbook of business groups (pp. 15-66). Oxford: Oxford University Press. DOI: 9780199552863.001 .0001

Costa, A. (2007). Gestão dos herdeiros ou de profissionais nas empresas familiares: O caso da Perdigão. Revista de Economia Contemporânea, 11(2), 197-225.

Cuervo-Cazurra, A. (2007). Business groups and their types. Asia Pacific Journal of Management, 23(4), 419-437. DOI: 10.1007/s10490-006-9012-5

Da Redação (2010). Sadia perde cerca de R\$ 2,5 bi com câmbio em 2008. Revista Exame. Recuperado de https://exame.com/negocios/sadia-perde-cerca-r-2-5-bi-cambio-2008-diz-brascan$417570 /$

Dalla, A. (2005). Sucessão e sucesso nas empresas familiares. Curitiba: Juruá Editora.

Donneley, R. (1976). A empresa familiar. São Paulo: Abril.

Fee, C. y Thomas, Sh. (2004). Sources of gains in horizontal mergers: Evidence from customer, supplier, and rival firms. Journal of Financial Economics, 74(3), 423-460. DOI: 10.1016/j.jfi neco.2003.10.002

Fernández-Pérez, P. y Lluch, A. (eds.). (2016). Evolution of family business: Continuity and change in Latin America and Spain. Cheltenham: Edward Elgar Publishing.

Flores, S., Campos, S. y Sonza, I. B. (2019). Propriedade piramidal sob a ótica da teoria institucional e redes sociais. Perspectivas Contemporâneas, 14(1), 26-49.

Gaj, L. (1989). Comentário sobre profissionalização na reportagem: A crise da sucessão. Boletim da Revista de Administração, 17.

Gedajlovic, E. y Shapiro, D. (2002). Ownership Structure and Firm Profitability in Japan. Academy of Management Journal, 45(3), 565-575. DOI: 10.5465/3069381

Gerlach, M. (1992). Alliance capitalism: The social organization of Japanese business. Berkeley: Univ. of California Press.

Gersick, K., Hampton, D. y Lansberg, I. (1998). De geração para geração. Ciclos de vida das empresas familiares. São Paulo: Negócio Editora.

Ghatak, M. y Kali, R. (2000). Diversified business groups in emerging economies. ICRA Bulletin: Money and Finance, 2(4), 20-31.

Gonçalves, R. (1991). Grupos econômicos: Uma análise conceitual e teórica. Revista Brasileira de Economia, 45(4), 491-518.

Gorgati, V. (2000). Os determinantes da estrutura de capital de empresas familiares brasileiras durante os processos sucessórios. Contribuições à teoria da firma (Tese de mestrado). Universidade de São Paulo, Brasil. 
Granovetter, M. (2005). Business Groups and Social Organization. En N. Smelser y R. Swedberg (eds.), The handbook of economic sociology. Princeton-New York: Princeton University Press/Russell Sage Foundation.

Guillén, M. (2010). Capability building in business groups. En A. Colpan, T. Hikino y J. Lincoln (eds.), The Oxford handbook of business groups (pp. 743-762). Oxford: Oxford University Press. DOI: 10.1093/oxfordhb/9780199552863.001.0001

Hosken, D. y Simpson, J. (1998). Are Retailing Mergers Anticompetitive? An Event Study Analysis (Núm. Working Paper 216; pp. 1-36). Federal Trade Commission. Recuperado de https://www.ftc.gov/reports/are-retailing-mergers-anticompetitive-event-study-analysis

Instituto Brasileiro de Geografía e Estatística (2000). Brasil: 500 anos de povoamento. Rio de Janeiro: Ministério do Planejamento, Orçamento e Gestão/IBGE. Recuperado de https:// brasil500anos.ibge.gov.br/

Keister, L. (1998). Engineering Growth: Business Group Structure and Firm Performance in China's Transition Economy. American Journal of Sociology, 104(2), 404-440. DOI: 10.1086/ 210043

Khanna, T. y Yafeh, Y. (2010). Business Groups in Emerging Markets: Paragons or Parasites? En A. Colpan, T. Hikino y J. Lincoln (eds.), The Oxford handbook of business groups (pp. 575-601). Oxford: Oxford University Press. DOI: 10.1093/oxfordhb/9780199552863.001.0001

Khanna, T. y Rivkin, J. W. (2001). Estimating the performance effects of business groups in emerging markets. Strategic Management Journal, 22(1), 45-74. DOI: 10.1002/1097-0266(200 101) $22: 1$

Leach, W. (1984). Transformations in a Culture of Consumption: Women and Department Stores, 1890-1925. The Journal of American History, 71(2), 319-342. DOI: 10.2307/1901758

Lee, K. y Sam-Kang, Y. (2010). Business Groups in China. En A. Colpan, T. Hikino y J. Lincoln (eds.), The Oxford handbook of business groups (pp. 209-236). Oxford: Oxford University Press. DOI: 10.1093/oxfordhb/9780199552863.001.0001

Lodi, J. (1989). O fortalecimento da empresa familiar. Rio de Janeiro: Pioneira.

Machado, R. (1996). Estratégias empresariais: Um estudo de grupos industriais nacionais (19801993). Nova Economia, 6(2), 84-110.

Martins, L. (1965). Os grupos bilionários nacionais. Revista do Instituto de Ciências Sociais, 2(1), $79-116$.

Menezes, R. (2008). Especial edição impressa: De Santa Catarina para o mundo. Revista Portuária: Economia e Negócios. Recuperado de http://www.revistaportuaria.com.br/noticia/2718

Miyajima, H. y Kawamoto, S. (2010). Business Groups in prewar Japan: Historical formation and legacy. En A. Colpan, T. Hikino y J. Lincoln (eds.), The Oxford handbook of business groups (pp. 97-126). Oxford: Oxford University Press. DOI: 10.1093/oxfordhb/9780199552863 .001 .0001

Montmorillon, B. (1986). Les groupes industriels: Analyse structurelle et stratégique. París: Economica.

Muritiba, S., Muritiba, P., Domingues, L., Di-Dio, G. y Zavarizzi, F. (2016). Governança corporativa e sucessão em empresas familiares. Revista de Carreiras e Pessoas, 6(3), 346-357. DOI: 10.20503/recape.v6i3.31062

Nogueira, R. (1984). Empresas familiares: Analisis organizacional y social. Buenos Aires: Macchi. Perdigão (s/f). Relatórios Anuais (1970-2009). 
Perotti, E. y Gelfer, S. (2001). Red barons or robber barons? Governance and financing in Russian figs (Discussion Paper Núm. 2204). Centre for Economic Policy Research. Recuperado de: https://ideas.repec.org/a/eee/eecrev/v45y2001i9p1601-1617.html

Romano, P. y Almeida, V. (2015). Análise dos Efeitos em Mercado de Capitais Decorrentes de Fusões: O Caso BRF S.A. Revista de Administração Contemporânea, 19(5), 606-625. DOI: 10.1590/1982-7849rac20151890

Rosenblatt, P. (1995). La familia en la empresa: Comprender y resolver los problemas que enfrentan las familias empresarias. Buenos Aires: El Ateneo.

Sarkar, J. (2010). Business Groups in India. En A. Colpan, T. Hikino y J. Lincoln (eds.), The Oxford handbook of business groups (pp. 94-321). Oxford: Oxford University Press. Recuperado de 10.1093/oxfordhb/9780199552863.001.0001

Sereia, V. (2011). Trajetória Competitiva e a internacionalização da Empresa Perdigão. Internext, Revista Eletrônica de Negócios Internacionais da ESPM, 6(2), 138-164.

Tassara, H. y Scapin, A. (1996). Perdigão uma trajetória para o futuro. Videira: Empresa das Artes.

Valadare, S. y Leal, R. (2000). Ownership and control structure of Brazilian companies. Abante, 3(1), 29-56.

Williamson, O. (1975). Markets and hierarchies: Analysis and antitrust implications. Nueva York: Free Press.

Yiu, D., Lu, Y., Bruton, G. y Hoskisson, R. (2007). Business Groups: An Integrated Model to Focus Future Research: Business Groups. Journal of Management Studies, 44(8), 1551-1579. DOI: $10.1111 /$ j.1467-6486.2007.00735.x 